\title{
Thyroid hormone-mediated negative transcriptional regulation of Necdin expression
}

\author{
Maria Nygård, Nathalie Becker ${ }^{1}$, Barbara Demeneix ${ }^{1}$, Katarina Pettersson and \\ Maria Bondesson
}

Department of Biosciences at Novum, Karolinska Institutet, 14157 Huddinge, Sweden

${ }^{1}$ UMR 5166 CNRS/MNHN, 75231 Paris Cedex 05, France

(Requests for offprints should be addressed to M Bondesson; Email: maria.bondesson@biosci.ki.se)

\begin{abstract}
Unliganded thyroid hormone receptors (apoTRs) repress transcription of hormone-activated genes by recruiting corepressors to the promoters. In contrast, on promoters containing so-called negative thyroid hormone response elements (nTREs), apoTRs activate transcription. A number of different molecular mechanisms have been described as to how apoTRs activate transcription varying with the target gene of the study. Here we demonstrate that thyroid hormone regulates the transcription of the Necdin gene, a developmentally regulated candidate gene for the genomic imprinting-associated neurobehavioural disorder, Prader-Willi syndrome. ApoTRs activate Necdin expression through an nTRE in its promoter, downstream of the transcription start site. The nTRE of the Necdin gene resembles the nTREs of the TSH $\beta$ genes of the hypothalamus-pituitary-thyroid axis in the sequence, position in the promoter, and mode of activation. We show that this group of nTRE-driven genes shares the requirements for binding of the retinoic $X$ receptor and nuclear receptor corepressor/silencing mediator of retinoid and thyroid hormone receptors (NCoR/SMRT) for full ligand-independent activation, whereas there is no need for association of the p160 family of coactivators. In accordance with the requirement for corepressors, Necdin expression is influenced by deacetylase activity, suggesting that histone deacetylases and corepressors as well could function as activators of transcription, depending on the promoter context.
\end{abstract}

Journal of Molecular Endocrinology (2006) 36, 517-530

\section{Introduction}

Thyroid hormone (3,5,3-tri-iodothyronine; T3) is an essential regulator of brain development. Supporting this notion, congenital hypothyroidism results in severe and irreversible mental retardation. Thyroid hormones in the brain are strictly regulated both temporally and spatially (Quignodon et al. 2004), leading to the control of specific and critical aspects of cerebellar development. The restricted pattern of T3 in the developing fetus is controlled by the interplay of the deiodinases (reviewed by Bianco et al. 2002), which convert T3 to inactive isoforms of the hormone and vice versa. In line with the controlled and heterogeneous spatio-temporal pattern of T3 signalling in the brain, T3 has been suggested to be an instructive factor for specific steps of cell differentiation, such as differentiation of oligodendrocyte precursor cells and differentiation of Purkinje cells (reviewed by Rogister et al. 1999). It has also recently been shown that $\mathrm{T} 3$ promotes neuronal differentiation of embryonic stem cells in culture (Liu et al. 2002). T3 also controls other events in the developing brain such as migration of postmitotic granule cells (reviewd by Zoeller \& Rovet 2004).
Many of the effects of T3 on developmental processes in the brain can be correlated with the controlled expression of specific proteins. A well-studied example is the T3-induced activation of myelin basic protein, proteolipid protein, and myelin-associated glycoprotein expression during oligodendrocyte differentiation (reviewed by Rogister et al. 1999). Recently reported is the regulation of retinoic acid receptor-related orphan receptor (ROR) alpha by T3 in the brain, supported by the notion that the severe cerebral abnormalities resulting from $\mathrm{T} 3$ deficiency resembles the phenotype of mice with disruption of the ROR alpha gene (Vasudevan et al. 2005). The use of micro arrays has greatly increased the number of candidate target genes for thyroid hormone during brain differentiation (Poguet et al. 2003, Miller et al. 2004). However, the biological functions of many of these genes, as well as the question as to whether they are direct thyroid hormone target genes, remain to be investigated.

The thyroid hormone receptors (TRs) are members of the large nuclear receptor family of transcription factors. As with other members of this superfamily, TR contains an N-terminal domain (A/B), an activation function (AF)-1 domain, a DNA-binding domain (DBD) and a 
ligand-binding domain (LBD), which undergoes a conformational change upon hormone binding. The TRs can bind to thyroid hormone response elements (TREs) either as a homodimer or as a heterodimer with retinoid X receptor (RXR). The association of these complexes with DNA activates or represses transcription in a ligand-dependent manner. The TR complex interacts with co-factors, which mediate the T3 signalling to the basal transcriptional machinery. Depending on whether the gene promoter contains positively or negatively regulated $\mathrm{T} 3$ response elements, T3 either increases or decreases the expression of the target gene. On positive T3 response elements (pTREs), the unliganded TR (apoTR) suppresses basal gene transcriptional activity by interacting with corepressors such as nuclear receptor corepressor (NCoR) and silencing mediator of retinoid and thyroid hormone receptors (SMRT) (reviewed by Eckey et al. 2003). The corepressors are associated with histone deacetylases (HDACs), which modify the chromatin into a compact and transcriptionally silent structure. The binding of the hormone to the receptor (holoTR) leads to conformational changes of the TR, which releases the corepressor complex and recruits the coactivators such as steroid receptor coactivator 1 (SRG-1 or NCoA-1), SRC-2 (GRIP1, TIF2, or NCoA-2), TRAP 220 and CBP/p300 (reviewed by Moore \& Guy 2005). The coactivators possess or recruit proteins with histone acetyltransferase activity, which remodels the chromatin to an open structure allowing for transcription.

The mechanism for regulation of transcription of negative T3 response elements (nTREs) is not well defined. A number of genes has been reported to be activated by apoTRs and these genes are repressed in the presence of ligand. Other genes, such as the thyrotrophin beta $(\mathrm{TSH} \beta)$ gene, require other transcription factors for activation, but are still repressed by liganded TRs (Nakano et al. 2004). Conflicting results have been published on the requirement of DNA binding of TR to nTREs and on the roles of different cofactors for regulation of genes driven by nTREs, suggesting that there may exist several mechanisms operating on genes negatively regulated by TRs by different mechanisms. One mechanism as to how T3 represses transcription is that TRs pose inhibitory effects on other transcription factors at certain promoters. The T3-mediated inhibition of the activity of GHF-1/Pit-1, CREB and AP-1 are examples that may not require direct binding of TR to the DNA (Lopez et al. 1993, Sanchez-Pacheco et al. 1995, Mendez-Pertuz et al. 2003, Furumoto et al. 2005). Other genes, such as the thyrotrophin releasing hormone (TRH) and TSH genes of the hypothalamus-pituitary-thyroid axis, require direct binding of TR to the promoter for their regulation (Satoh et al. 1999, Shibusawa et al. 2003). Furthermore, it has been suggested that ligand-dependent recruitment of
HDAC2 contributes to the negative regulation of the TSH $\beta$ promoter (Sasaki et al. 1999). Examples of other genes that require direct binding by TR for its negative regulation are the $\mathrm{E} 2 \mathrm{~F}-1, \mathrm{CD} 44$, prohormone convertase 1 and 2 (PG1 and 2), sodium-potassium adenosine triphosphate alpha 3 and the type 1 deiodinase genes, the latter in a tissue-specific manner (Chin et al. 1998, Nygård et al. 2003, Kim et al. 2004, Shen et al. 2004, 2005). A third mechanism involves an overlap of the nTRE with SP-1 sites, such that TR in the presence of ligand binds to DNA, which precludes SP-1 from binding (Villa et al. 2004). By a similar mechanism, a number of promoters have been reported to contain composite sites for TR and 11-zinc-finger CCTC-binding factor (CTCF), in which mutations in the CTCF response element abolishes the negative regulation by TR (Awad et al. 1999). Finally, it has been shown that binding of TR to an nTRE in the growth hormone $(\mathrm{GH})$ promoter is associated with histone $\mathrm{H} 3$ acetylation. In this case, T3 causes release of the receptor from the promoter as well as disappearance of acetylated histones at the gene (Sanchez-Pacheco \& Aranda 2003).

Whether or not NCoR and SMRT are involved in the regulation of transcription from genes driven by nTREs has been discussed in a number of articles (Horlein et al. 1995, Hollenberg et al. 1996, Satoh et al. 1999, Tagami et al. 1999, Nakano et al. 2004, Kim et al. 2005). Berghagen et al. (2002) report that SMRT functions as a coactivator for T3-independent activation of nTREs and that a TR mutant that is unable to bind to SMRT and NCoR is deficient in T3-independent activation. Accordingly, it was recently reported that a natural splice variant of NGoR, but not the full length NGoR, functions as a coactivator of apoTRs in yeast (Meng et al. 2005). On the other hand, over-expression of NCoR and SMRT did not affect T3-independent activation of TRH expression in the paraventricular nucleus in mice brains (Becker et al. 2001). Other factors that either enhance or are completely required for negative regulation are RXRs (Chin et al. 1998, Laflamme et al. 2002).

Necdin is a 325-amino acid residue protein that originally was cloned from differentiated P19 embryonal carcinoma cells (Maruyama et al. 1991). Necdin is homologous to the large family of melanoma antigen proteins, normally expressed in stem cells and testis, but also frequently expressed in tumours (reviewed by Ohman Forslund \& Nordqvist 2001). Studies in vitro have suggested that Necdin may be a neuron-specific growth suppressor that facilitates cell cycle exit and neuronal differentiation and inhibits apoptosis (reviewed by Yoshikawa 2000). The Necdin gene is expressed predominantly in postmitotic neurons in the central nervous system and its expression is regulated during embryonic development. Necdin begins to be expressed at embryonic day (E) 10, around the time that the first 
diencephalic neurons become post-mitotic. From E10 to E12, in both central and peripheral nervous systems, Necdin expression correlates with the initial formation of all post-mitotic neurons. After E13, Necdin expression remains high in both embryonic and adult thalamus, hypothalamus and pons, but diminishes in other post-mitotic structures such as the neocortex (Andrieu et al. 2003). Necdin knockout mice show a phenotype resembling the Prader-Willi syndrome, a genomic imprinting-associated neurobehavioural disorder, suggesting that the absence of Necdin impairs neuronal differentiation or maturation (Gerard et al. 1999, Muscatelli et al. 2000, Andrieu et al. 2003). Recently, it was shown that Necdin is also expressed in non-neuronal cells such as skeletal myocytes, chondrocytes, adipocytes, and skin fibroblasts (Taniguchi et al. 2000, Boeuf et al. 2001, Hu et al. 2003).

Here we demonstrate that thyroid hormone regulates the transcription of the Necdin gene. A putative nTRE was identified in the Necdin gene, downstream of the transcriptional start site, which, together with the full Necdin promoter, was cloned to drive the expression of reporter genes. In transient transfections, the Necdin reporter and the Necdin nTRE reporter were activated by apoTRs. The nTRE of Necdin alone was sufficient for thyroid hormone regulation of the reporter gene, indicating it to be essential for T3-dependent regulation. DNA binding of TR was required for regulation of Necdin, and TR was found to bind to the nTRE together with RXR both in in vivo and in vitro experiments. Activation of the Necdin gene in the absence of T3 required RXR and was stimulated by corepressors such as NCoR, but not by coactivators from the p160 family. Activation of Necdin expression also required functional deacetylase activity, suggesting that HDACs may play a role in activation of transcription on certain promoters.

\section{Materials and methods}

\section{Plasmid constructs}

The chicken TR $\beta 0$ gene was cloned into the pSG5 expression vector (Sjoberg \& Vennstrom 1995). The pTRE reporter plasmid is the pTLUC109F2Tx2, containing two everted TR response elements (Andersson \& Vennstrom 2000). pSG5-mRXR $\beta$ has been described previously (Sjoberg \& Vennstrom 1995). The Necdin promoter reporter (Necdin) construct was cloned by insertion of a $192 \mathrm{bp}$ PCR amplified and gel purified fragment of the Necdin promoter, ranging from -87 to +110 , into the KpnI and HindIII sites of the pGL2-Basic vector (Promega Corp., Madison, WI, USA). The primers used for PGR amplification were: forward primer 5'-GG GGT ACG CTG CAG TCT TCT GGG TTC CGA ACA GGG ATG $\mathrm{C}$ and reverse primer 5'-GG AAG CTT CAG GTC CTT ACT TTG TTG CGA GGT GTG T.

The long Necdin promoter reporter construct (Necdin-long) was cloned by insertion of a 932 bp PCR amplified fragment of the Necdin promoter, ranging from -823 to +110 , into the XhoI and HindIII sites of the pGL2-Basic vector using forward primer 5 '-GC CTG GAG CTG CAG GTG ACG TAA TAG AAA TGG AGA $G$ and reverse primer 5'-GC AAG CTT CAG GTC CTT ACT TTG TTC CGA CGT GTG T. A mutant Necdin long luciferase construct (Necdin long mut) was cloned exactly as the Necdin-long construct except using the reverse primer: 5'-GC AAG CTT CAG GTG GTT GAG TTG TTG CGA GGT GTG T. The reverse primer introduces three point mutations (shown in bold) in the construct (amino acid change S5 L).

The Z-Necdin minimal reporter plasmid (Z-Necdinluciferase) was cloned by insertion of a DNA oligomer into the KpnI and XhoI sites of the pGL2-promoter vector (Promega Corp.). The sequence of the inserted oligomer was: 5'-C CTG CAG ACA TGT CGG AAC AAA GTA AGG $\mathrm{C}$ and 3'-ACT GGG ACG TGT GTA CAG GGT TGT TTG ATT GGG AGG T.

\section{Cell culture and transfections}

JEG-3 or CV-1 cells were plated in a 24-well plate in DMEM (Biochrom, Berlin, Germany) supplemented with 10\% fetal calf serum (FCS). One day later, the medium was replaced with DMEM supplemented with $10 \%$ FCS depleted of T3 and thyroxine by ion exchange resin (Samuels et al. 1979). Approximately $1 \mathrm{~h}$ later, the cells were cotransfected by the calcium phosphate method with expression vectors encoding $100 \mathrm{ng}$ TR, 5-20 ng RXR $\beta$ and $200 \mathrm{ng}$ of reporter constructs. The cells were maintained in the presence or absence of $1 \mu \mathrm{M}$ T3 (Sigma, St Louis, MO, USA) and trichostatin A (TSA, Sigma Aldrich) in concentrations from $10 \mathrm{nM}$ to $100 \mathrm{nM}$ when indicated, harvested $24 \mathrm{~h}$ after hormone treatment and assayed for luciferase activity. All transfections were performed at least three times, employing duplicate sample points in each experiment.

\section{Protein extraction and Western blot}

P19 cells were lysed in lysis buffer (Tropix) supplemented by $50 \mu \mathrm{M}$ dithiothreitol and proteinase inhibitors (Complete Mini, Roche). Lysates were cleared by centrifugation for $15 \mathrm{~min}$ at $14000 \mathrm{~g}$. Protein extracts $(50-100 \mu \mathrm{g})$ were separated by $10 \%$ SDS-polyacrylamide gel electrophoresis and transferred to nitrocellulose transfer membranes. For western blots, antibodies against Necdin (AB 18554, Abcam, Cambridge, UK), actin (SG-8452, Santa Gruz Biotechnology, Santa Cruz, CA, USA), TR $\beta$ (MA1-215, ABR, Colorado, USA) or TR $\alpha$ (PA1-211A, ABR) were used diluted 1:1000. 
Proteins were visualized using enhanced chemiluminescence (ECL Western Blot Detection Reagents, Pharmacia Biosciences) according to the manufacturer's instructions.

\section{Gel retardation assays}

Binding studies of receptor/DNA complexes were carried out essentially as previously described (Nygård et al. 2003). Appropriate receptor-encoding cDNAs were cloned into the pATA-18gpt, used for recombination into the Vaccinia genome following infection into HeLa cells, and the nuclear extract was prepared as previously described (Nygård et al. 2003). One to three micrograms of these nuclear extracts were incubated for $15 \mathrm{~min}$ on ice with approximately $4 \mathrm{ng}{ }^{32} \mathrm{P}$-labelled oligonucleotides in band shift buffer (4\% Ficoll, $80 \mathrm{mM} \mathrm{KCl}$, $10 \mathrm{mM}$ HEPES at pH 7.9, $5 \mathrm{mM} \mathrm{MgCl}_{2}$ and $100 \mu \mathrm{g} / \mathrm{ml}$ poly $\mathrm{dIdC}$ ) in the presence or absence of $1 \mu \mathrm{M}$ T3. Complexes were separated on a running 6\% nondenaturating polyacrylamide gel. The oligonucleotide probes were annealed, and labelled using the Klenow fragment of Escherischia coli polymerase I (New England Biolabs, Ipswich, Massachusetts, USA). The sequences of the probes were: DR4 probe 5'-AGCTTCAGGTC ACTTCAGGTCA, Necdin-Z probe 5'-GGGACATGT CGGAACAAAGTAAGG.

The antibodies used for supershifts were anti-TR $\beta$ (MA1-215, ABR) and anti-oestrogen receptor (ER $\alpha$, SC-786, Santa Cruz Biotechnology).

\section{RNA extraction, cDNA synthesis and quantitative RT-PCR}

P19 cells were grown in 10\% T3-depleted FCS and $100 \mathrm{nM}$ all trans retinoic acid (AT-RA) (Sigma) for $72 \mathrm{~h}$ to induce Necdin expression. T3 $(1 \mu \mathrm{M})$ was added and the cells were incubated for another 1, 3, and $6 \mathrm{~h}$. RNA was extracted using Trizol (Invitrogen). RNA extraction and cDNA synthesis were performed as described (Muller et al. 2002). Quantitative real-time PGRs were performed in an ABI PRISM Model 7700 sequence detector (PE Applied Biosystems) using Platinum SYBR Green qPCR (Invitrogen) with forward primer at position +501 relative to the transcriptional start site $5^{\prime}$-GAG TTT GCG CTG GTC AAA GG and a reverse primer 5'-CAT GGG CAT AGG GTT GTT GAG. The 18S rRNA gene was used as a reference gene using forward primer 5' CCT GCG GGT TAA TTT GAG TCA and reverse primer 5' AGG TAT CAA TCT GTC AAT CGT GCT. Quantitation of Necdin mRNA expression was determined as described previously (Chakrabarti et al. 2002).

\section{Chromatin immunoprecipitation assays}

Chromatin immunoprecipitation assays (ChIP) were preformed as described previously (Burakov et al. 2002).
Murine P19 embryonic teratocarcinoma cells, which have been shown to express the Necdin gene after retinoic acid (RA)-induced differentiation, were used (Maruyama et al. 1991). P19 cells were treated with $1 \mu \mathrm{M}$ all-trans RA for $24 \mathrm{~h}$. After $24 \mathrm{~h}$, cells were treated with or without $1 \mu \mathrm{M}$ T3 for $1 \mathrm{~h}$. After T3 treatment, cells were fixed with $1 \%$ formaldehyde for $20 \mathrm{~min}$ at room temperature and quenched with $0.125 \mathrm{M}$ glycine. The cells were washed twice in ice-cold phosphate-buffered saline and the pellets were resuspended in $100 \mu \mathrm{l}$ RIPA lysis buffer (50 mM Tris, $\mathrm{pH} 8 \cdot 0,1 \mathrm{mM}$ EDTA, 0.5 mM EGTA, $1 \%$ Triton X-100, 0.1\% sodium deoxycholate, $140 \mathrm{mM} \mathrm{NaCl}$ and protease inhibitors) and incubated at $4{ }^{\circ} \mathrm{C}$ for $10 \mathrm{~min}$. Samples were sonicated to shear DNA to an average length of $600-800 \mathrm{bp}(8 \times 10 \mathrm{~s})$ and the sample was centrifuged for $10 \mathrm{~min}$ at $14000 \mathrm{~g}, 4{ }^{\circ} \mathrm{C}$. The cell lysates were precleared by incubation with protein G-sepharose beads and then incubated with antibodies against TR $\beta$ (MA1-215, ABR), RXR $\beta$ (PA1-815, ABR), NCoR (PA1-844, ABR), acetylated histone H3 (\#06-599, Upstate, Dundee, UK), acetylated histone H4 (\#06-866, Upstate) or an unspecific antibody. Protein-DNA complexes were collected with protein G-sepharose beads followed by several rounds of washing (Burakov et al. 2002). Bound DNA-protein complexes were eluted in $100 \mu$ l elution buffer $(10 \mathrm{nM}$ Tris, $1 \mathrm{nM}$ EDTA, $1 \%$ SDS) and incubated at $66^{\circ} \mathrm{C}$ overnight to reverse cross-linked DNA. DNA fragments were isolated and purified using QIAquick Spin Kit (Qiagen). A $294 \mathrm{bp}$ fragment of the immunoprecipitated Necdin promoter was PCR amplified, starting at position -30 relative to the transcriptional start site. The forward primer was 5'-CTG CTG CGG AAG GGG CAG TGG TCA $G$ and the reverse primer was $5^{\prime}$-GAG GGG TGT TGG GGT GCG ATA GGG. Amplified fragments were separated on a $2 \%$ agarose gel.

\section{Results}

\section{The Necdin promoter is regulated by thyroid hormone receptors}

We have previously described how transcription of the E2F-1-promoter is regulated by TRs (Nygård et al. 2003). Transcription from the E2F-1 promoter is activated by TR in the absence of T3, and silenced in the presence of $\mathrm{T} 3$. We have further identified and functionally characterized an nTRE in the E2F-1 promoter that is sufficient for mediating the TRdependent transcriptional regulation. This so called Z-element is positioned at nucleotides -190 to -221 of the $\mathrm{E} 2 \mathrm{~F}-1$ promoter and resembles, to some extent, the nTREs found in the TSH $\beta$ promoter.

To identify genes that are negatively regulated by T3, we performed database homology searches to screen for genes containing conserved Z-element sequences similar 

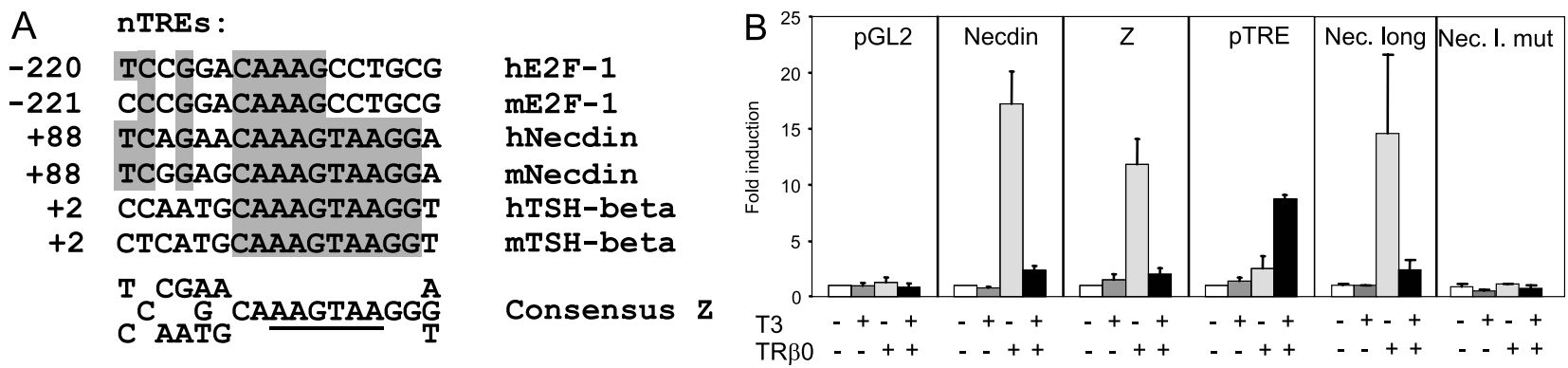

Figure 1 (A) Sequence comparison of the negative thyroid hormone response elements, nTRE, from the human and mouse E2F-1, Necdin and TSH promoters. Conserved nucleotides between the nTREs of Necdin and the E2F-1 and/or TSH are marked in grey. The consensus sequence is based on the fact that a specific nucleotide is located at a specific position at least twice by comparison with the six nTREs. A potential TRE half site is underlined. (B) TR regulates transcription of the Necdin promoter. An expression plasmid of cTR $\beta 0$ was cotransfected with the cloning vector (pGL2) alone, the Necdin promoter coupled to a luciferase reporter construct (Necdin), the Necdin-minimal reporter construct (Z), a longer Necdin promoter construct containing nucleotides -823 to +110 of the Necdin promoter (Nec. long), a Necdin reporter containing three point mutations in the Z-element (Nec. I. mut), or a reporter construct containing a positively regulated TRE (pTRE) into JEG-3 cells. Cells were grown in the absence or presence of $1 \mu \mathrm{M} \mathrm{T3}$ as indicated. The $y$-axis shows the degree of activation as a multiple of the luciferase assay value of the reporter vector alone (pGL2, Necdin, Z, Necdin long, Necdin long mut or pTRE). Standard deviations are shown from three independent experiments, each with triplicate samples.

to the one present in the E2F-1 promoter (Nygård et al. 2003). We found a number of genes containing potential nTRE sequences, one of them being the Necdin gene. In the Necdin gene, a Z-element, identical to that of the $\mathrm{TSH} \beta$ gene, was identified at nucleotide position +94 to +103 (Fig. 1A).

To investigate whether Necdin is a T3 responsive gene, the sequence from -87 to +110 of the Necdin promoter, containing the Z-element, was cloned into a luciferase reporter plasmid, at a position in front of the Simian virus 40 TATA-box. The Necdin promoter reporter construct was cotransfected with chicken TR $\beta 0$ into JEG-3 cells. TR $\beta 0$ efficiently activated the transcription from the Necdin promoter (17-fold) in the absence of $1 \mu \mathrm{M}$ T3. Addition of T3 reversed the apoTR-mediated activation of the Necdin promoter (Fig. 1B).

The sequence from +84 to +105 of the Necdin promoter, containing the Z-element, was cloned into a luciferase reporter plasmid in front of the Simian virus 40 TATA-box. The Z-Necdin reporter plasmid was cotransfected with TR $\beta 0$ in the presence and absence of $1 \mu \mathrm{M}$ T3. The Z-Necdin reporter construct was activated 12 -fold by TR in the absence of hormone and the addition of T3 repressed this activation (Fig. 1B). A reporter construct containing a pTRE was used as a control. The positive reporter construct was cotransfected with cTR $\beta 0$ in the absence and presence of T3. In the presence of $\mathrm{T} 3$, TR activated the transcription from the pTRE (Fig. 1B). Finally, we introduced three point mutations in the Necdin promoter in the Z-element, which substitutes nucleotides AGT at position +98 relative to the transcription start site with GTG (Necdin long mut). These three nucleotides are absolutely required for TR regulation of the Z-element of the E2F-1 promoter as defined previously (Nygård et al. 2003). Regulation of transcription of this reporter by TR was now abolished (Fig. 1B). Taken together, these results show that the Z-element present in the Necdin promoter is sufficient for activation by TR in the absence of T3 and for repression in the presence of T3.

\section{Repression of Necdin transcription by T3 in P19 cells}

We next wanted to analyse the regulation of Necdin in vivo. Necdin shows low or absent expression in most cell lines, but is expressed in the murine embryonic teratocarcinoma cell line P19 after differentiation by RA (Maruyama et al. 1991). Thus, we treated P19 cells with $100 \mathrm{nM}$ AT-RA for $72 \mathrm{~h}$ before adding $1 \mu \mathrm{M}$ T3 to the cells. RNA expression of the Necdin gene was detected by reversed transcription coupled to quantitative real-time PCR. As shown in Fig. 2A, the levels of Necdin mRNA decreased after 1,3 and $6 \mathrm{~h}$ of T3 treatment. The decrease in mRNA levels was accompanied by a decreased expression of Necdin protein levels as detected by Western blot, demonstrating that T3-dependent down-regulation of the Necdin transcription is concomitant with decreased levels of Necdin protein (Fig. 2B). P19 cells express both TR $\alpha$ and TR $\beta$, as detected by Western blot using isoform-specific antibodies (Fig. 2C). Thus, either one of the isoforms could mediate the T3-induced repression of Necdin expression in vivo.

\section{The role of cofactors for transcription of the Necdin promoter}

To analyse the requirement of different cofactors for TR regulation of promoters containing nTREs, we analysed a number of mutants in cTR $\beta$. The mutants were 
A

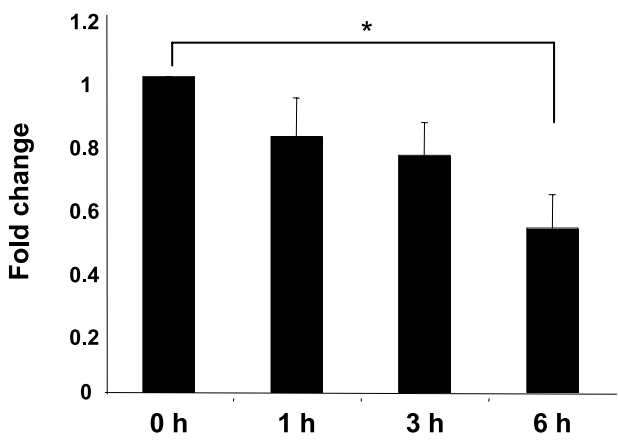

B
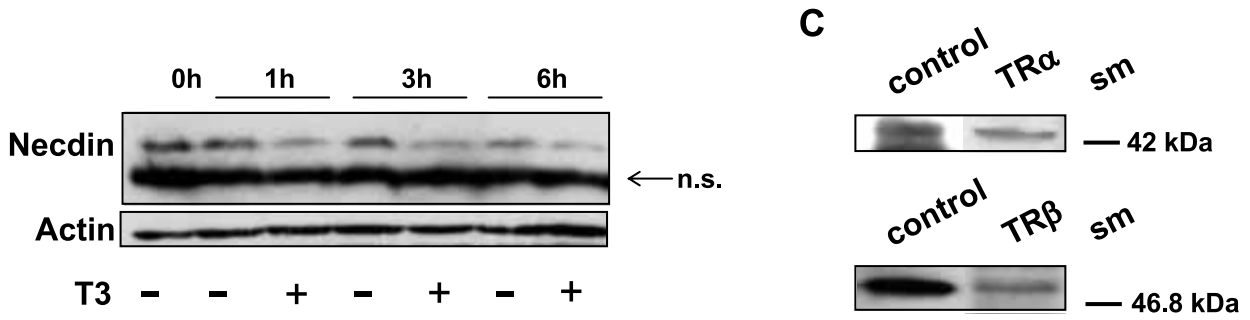

Figure 2 (A) T3 represses Necdin mRNA expression in P19 cells. Necdin expression in P19 cells was induced by retinoic acid (RA) treatment for $72 \mathrm{~h}$, followed by treatment with $1 \mu \mathrm{M}$ T3 for 1,3 or $6 \mathrm{~h}$. The mRNA levels were analysed by reversed transcription coupled to quantitative real-time PCR. Values are significant at a confidence level of $P<0.05\left(^{*}\right)$ by Student's $t$-test. (B) T3 decreases Necdin protein levels in P19 cells. Protein extracts were prepared in RA-differentiated P19 cells after 1, 3 or $6 \mathrm{~h}$ of $1 \mu \mathrm{M}$ T3 treatment. Protein extracts $(50 \mu \mathrm{g})$ were separated on a $10 \%$ polyacrylamide gel, transferred to nitrocellulose membranes and analysed by Western blot using an anti-Necdin antibody (AB-18554, Abcam) or an anti-actin antibody (SC-8452, Santa Cruz Biotechnology). n.s., nonspecific band. (C) P19 cells express both TR $\alpha$ and TR $\beta$. Western blot on P19 protein extracts using isoform-specific anti-TR antibodies (TR $\alpha$, PA1-211A; TR $\beta$, MA1-215, ABR). Vaccinia virus-produced TR $\alpha$ or TR $\beta$ in HeLa cells were used as positive controls. The size marker (sm) bands are indicated to the right.

chosen based on their altered capability to bind to certain coactivators and corepressors, such as the p160 coactivators and NcoR/SMRT, and they have all been characterized and described previously. The mutants and wild type (wt) TR $\alpha$ and TR $\beta$ were cotransfected into JEG-3 cells together with either the Necdin reporter or a pTRE reporter construct. Mutant L362 V does not bind to the p160 coactivator family (leucine at position 362 changed to valine; Collingwood et al. 1997). This mutant receptor functioned as the wt TR on the Necdin promoter, both in ligand-independent activation and ligand-dependent repression (Fig. 3). As expected, this mutant was deficient in ligand-dependent activation of transcription of a pTRE. Mutant P214R is defective in NGoR/SMRT binding (Nagaya et al. 1998). This mutant receptor only activated the Necdin promoter to a third of that of wt TR, indicating that binding of corepressors are required for full ligand-independent activation of the nTRE. However, on a pTRE, the corepressor binding mutant functioned as well as wt TR in terms of ligand-dependent activation. The RXR heterodimerization-deficient mutant (L336R) (Nagaya \& Jameson 1993) had lost its capacity to regulate transcription of both positive and negative TREs both in the presence and absence of T3, showing the crucial role of RXR in TR-mediated transcriptional regulation. DNA binding was also absolutely required for regulation of both pTREs and nTREs, as the DNA binding mutant (E33 G/G34S) was unable to activate either pTREs or nTREs. This mutant is not transcriptionally deficient, but its sequence recognition ability has been converted to bind to and activate a hybrid response element composed of GRE and TRE (Shibusawa et al. 2003). Thus, our results are in line with previously reported results that this mutant is defective in the regulation of TRH, TSH $\alpha$ and TSH $\beta$ as well as pTRE (Shibusawa et al. 2003). The mutant TRalpha $\Delta \mathrm{AF} 2$ has a very low ligand binding capacity and cannot interact with coactivators due to a nine amino acids deletion in helix 12 of the AF-2 domain (Barettino et al. 1994). This 

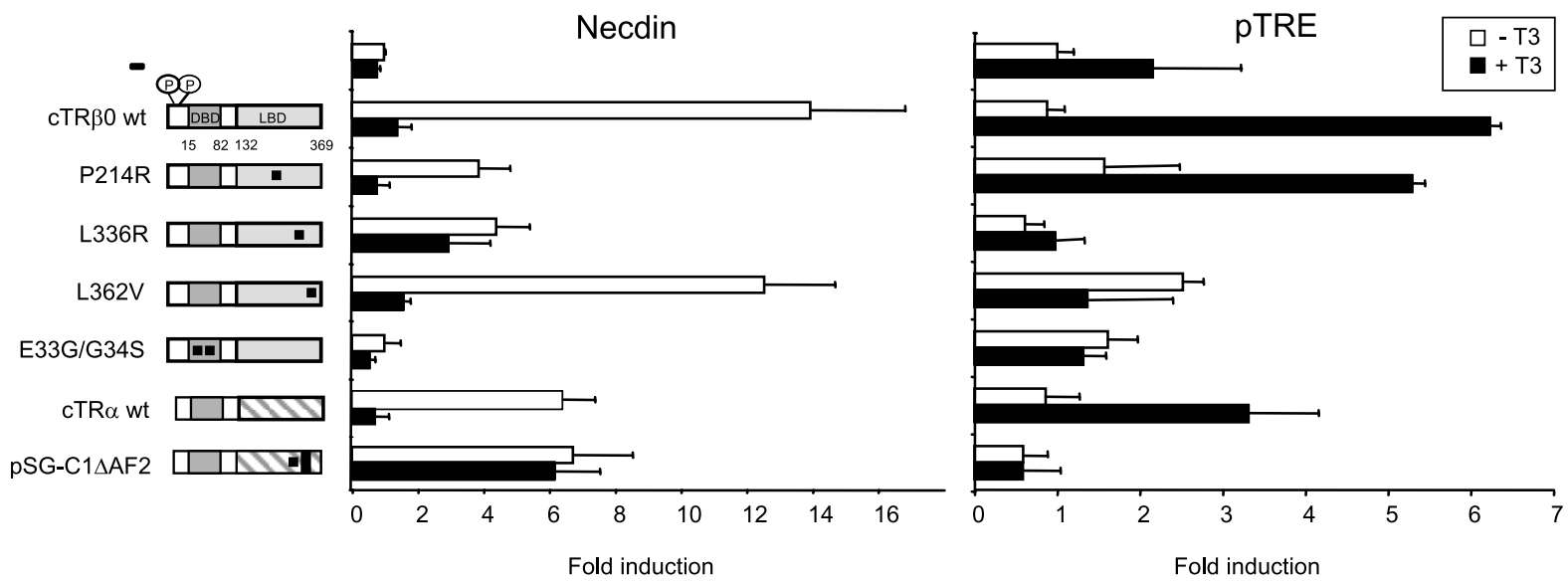

Figure 3 The influence of different mutations in TR on the regulation of Necdin transcription. Schematic presentations of the cTR $\beta 0$ and cTR $\alpha$ mutants are shown to the left. The positions of the mutated amino acids in relation to the translation start site are indicated. Expression plasmids for the different cTR $\beta 0$ mutants and the Necdin luciferase reporter construct (Necdin) or a positive thyroid hormone response element (pTRE) were cotransfected into JEG-3 cells. The cells were grown in the presence (solid bars) or absence (open bars) of $1 \mu \mathrm{M}$ T3 as indicated. The $x$-axis shows fold activation as a multiple of the luciferase value of the reporter vector for Necdin or pTRE alone. Standard deviations are shown from at least three independent experiments, each with triplicate samples.

mutant, which is possibly constitutively associated with corepressors, was found to be a constitutive activator of the Necdin promoter, i.e. T3-induced repression was completely lost. As expected, it was unable to activate transcription of the pTRE.

To further analyse the requirement of different cofactors for regulation of nTREs, expression plasmids encoding different cofactors were transfected together with TR $\beta 0$ and the Necdin promoter. To analyse the involvement of RXR, we used CV-1 cells, which express very low levels of RXR, in cotransfection experiments. Addition of RXR enhanced the activation of apoTR on the Necdin promoter in a dose-dependent manner, but had little affect on the T3-mediated repression (Fig. 4). These results indicate that RXR is required for full activation of nTREs in the absence of T3, possibly by stabilizing interaction with other intermediary factors, but is of less importance for T3-dependent repression of transcription. As expected, coexpression of RXR did not affect the activity of the TR mutant that is defective in RXR binding. Interestingly, cotransfection with increasing amounts of the corepressor NCoR into JEG-3 cells led to a dose-dependent increase in the ligand-independent activation of Necdin. The ligand-induced repression was not affected by NCoR (Fig. 5A). In contrast, coexpression of the coactivator, TIF2, had no effect on the activity of the Necdin reporter gene (Fig. 5B).

Collectively, our results show that DNA binding heterodimerization with RXR is required for both activation and repression of Necdin expression and that a functional $\mathrm{AF}-2$ is vital for T3-dependent repression of Necdin. Corepressor binding is required for activation of the Necdin promoter, whilst coactivator binding is not required for either activation or repression of Necdin. The corepressor NCoR coactivates the Necdin reporter in the absence of T3 whereas the coactivator TIF2 does not affect the T3-independent or the T3-dependent activity of Necdin. These results indicate that transcriptional activity of apoTR, as well as T3-dependent transcriptional repression on nTREs, utilizes a mechanism that is in contrast to ligand-induced activity on pTREs.

\section{Deacetylase activity influences ligand-independent activation of the Necdin genes}

When TR binds to a positive TRE in the absence of T3, it silences basal transcription by binding to corepressors. These corepressors form complexes with HDACs, which remodel the chromatin to a closed, transcriptionally inactive conformation. Also, HDAGs have been shown to regulate the acetylation status of non-histone targets such as p53 and several nuclear receptors (reviewed by Glozak et al. 2005). To test if HDACs are involved in the transcriptional regulation of genes containing negative TREs, we used trichostatin A (TSA), which is an inhibitor of deacetylase activity. JEG-3 cells were cotransfected with either the Necdin promoter reporter construct with cTR $\beta 0$ or the pTRE reporter construct in the absence or presence of hormone and TSA. The ligand-independent transcriptional activation of the Necdin reporter constructs was abolished when TSA was added (Fig. 6). In contrast, T3-induced repression of the reporter was not at all affected by TSA. When a positive TRE luciferase reporter construct was cotransfected with cTR $\beta$ o in the presence and absence of T3 and TSA, TSA amplified the T3-mediated activation of 


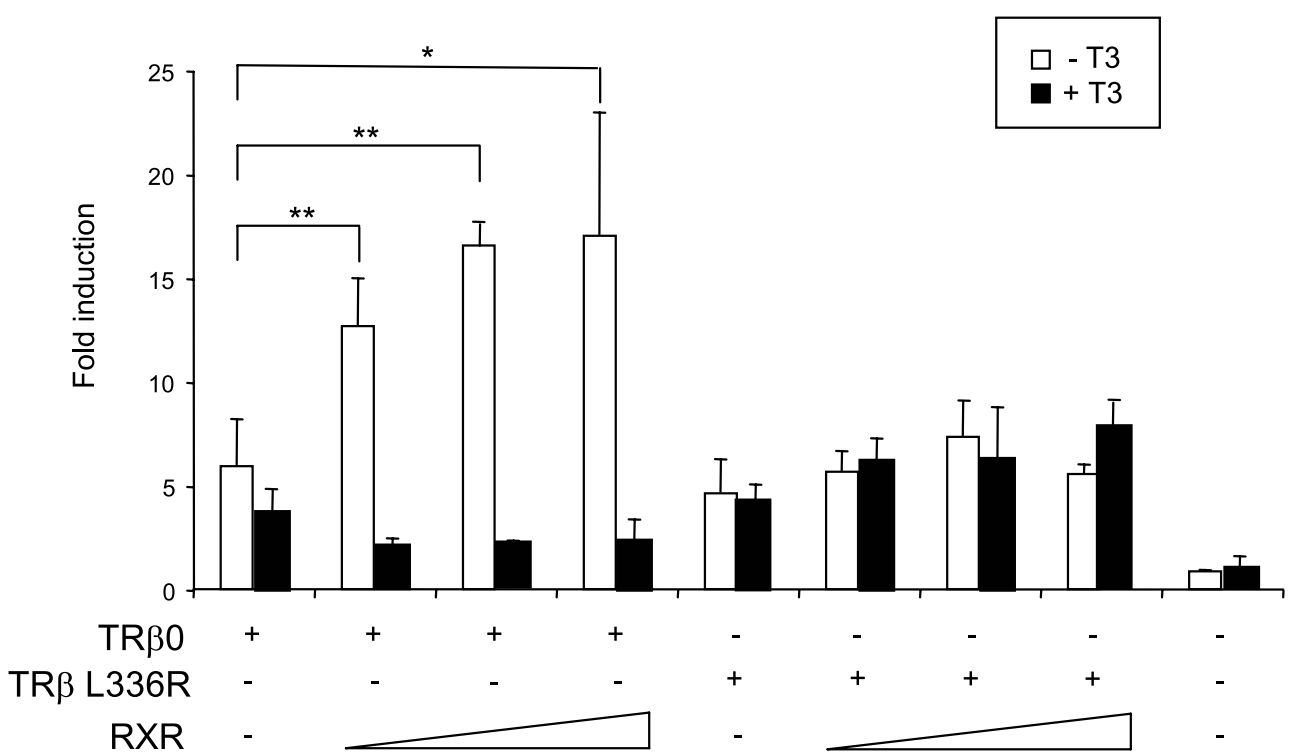

Figure 4 RXR potentiates the T3-independent activation of Necdin. CV-1 cells were cotransfected with the Necdin reporter construct, TR $\beta 0$ or TR $\beta$ mutant L336R and increasing concentrations of RXR expression plasmid. The cells were grown in the presence (solid bars) or absence (open bars) of $1 \mu \mathrm{M}$ T3 as indicated. The $y$-axis shows fold activation as a multiple of the luciferase value of the reporter vector for Necdin alone. Standard deviations are shown from at least three independent experiments, each with triplicate samples. Values are significant at a confidence level of $P<0.05\left(^{*}\right)$ or $P<0.01\left(^{* *}\right)$ by Student's $t$-test.

the reporter (Fig. 6). These results imply that deacetylation does not affect T3-dependent silencing of transcription of the Necdin promoter, but instead is involved in the ligand-independent activation, thus reinforcing the differences in the mechanisms behind TR-dependent transcriptional regulation of nTREs versus pTREs.

\section{TR binds to the nTRE of the Necdin gene}

To study if TR binds directly to the nTRE of the Necdin gene, electrophoretic mobility shift experiments were performed. Labelled Necdin nTRE oligo or a pTRE (DR4) oligo were incubated with HeLa cell extracts containing Vaccinia virus-produced TR $\beta 0$ or RXR. The DNA/protein complexes were separated on a polyacrylamide gel. The results showed that TR $\beta 0$ in complex with RXR efficiently bound to the Necdin nTRE (Fig. 7A). This complex was formed in the absence of T3, and addition of $\mathrm{T} 3$ reduced the amount of the complex. Anti-TR antibodies shifted the complex showing that TR was indeed present in the complex, whereas an unspecific antibody (in this case anti-oestrogen receptor) had no effect. Neither TR alone, nor RXR alone could bind nTRE efficiently. The pTRE was used as a control for migration of DNA-bound TR monomers and TR/RXR or TR/TR dimers as described previously (Nygård et al. 2003).
To further study the binding of TR to the promoter region of Necdin, ChIP experiments were performed. Briefly, murine P19 embryonic teratocarcinoma cells were treated with $100 \mathrm{nM}$ AT-RA for $72 \mathrm{~h}$ to induce Necdin expression. The cells were then grown with or without $1 \mu \mathrm{M}$ T3 for 1 or $6 \mathrm{~h}$, and fixed with $1 \%$ formaldehyde for $20 \mathrm{~min}$ at room temperature. The cell extracts were incubated with antibodies against TR $\beta$, RXR $\beta$, NCoR, acetylated histones $\mathrm{H} 3$ and $\mathrm{H} 4$ or an unspecific antibody. Semiquantitative PCR of the Necdin promoter followed immunoprecipitation. The results showed that TR $\beta$ and $\operatorname{RXR} \beta$ were associated with the Necdin promoter in the absence of T3 (Fig. 7B). However, T3 treatment for 1 or $6 \mathrm{~h}$ resulted in a release of binding of TR and RXR to the promoter. Surprisingly, NGoR was found to be associated with the Necdin promoter in the presence of $\mathrm{T} 3$ and to some extent in the absence of T3 at both time points. Neither did we detect any significant differences in the association of acetylated histones $\mathrm{H} 3$ and $\mathrm{H} 4$ to the Necdin promoter between T3-treated and -untreated cells (Fig. 7B).

Taken together, these in vivo and in vitro experiments show that TR and RXR bind as a heterodimer to the nTRE of the Necdin gene. Both in vitro and in vivo, the complex is primarily seen on the Necdin promoter in the absence of ligand. This observation is to some extent supported by our results from co-transfection of RXR 


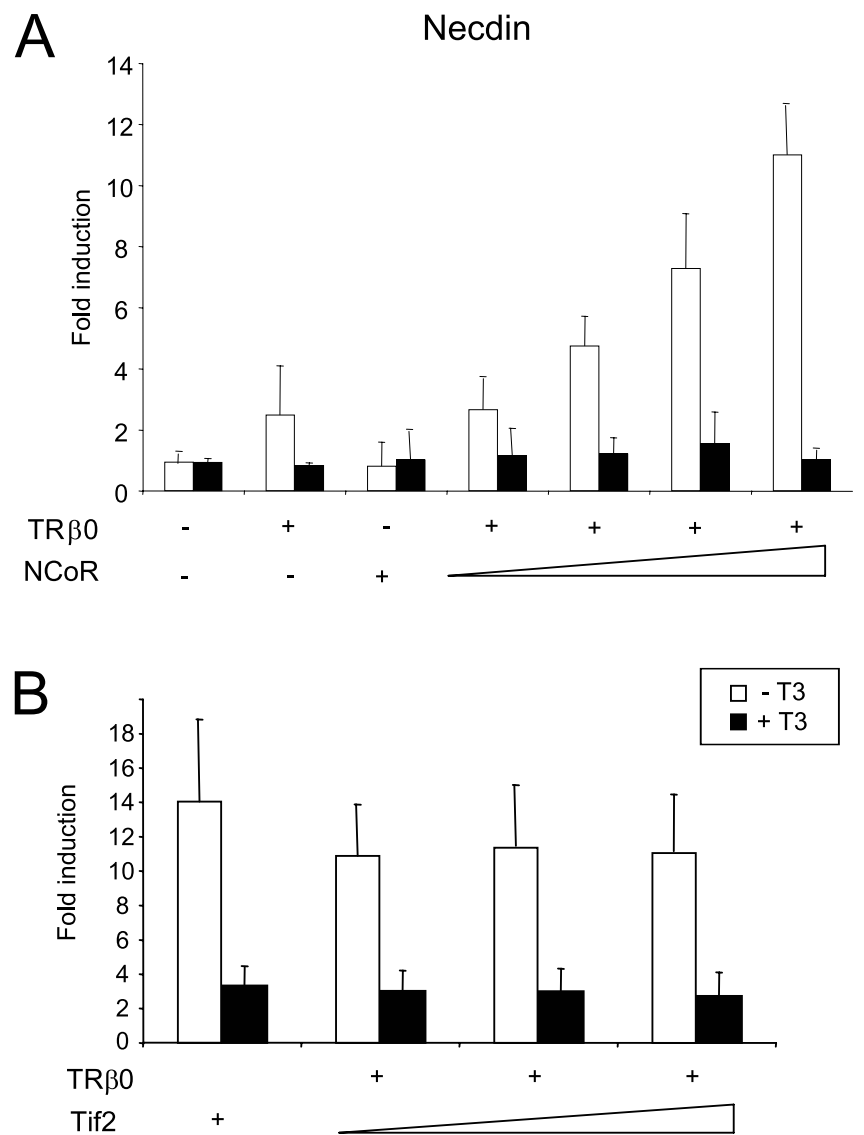

Figure 5 (A) The corepressor NCoR functions as a coactivator for TR on the Necdin promoter. JEG-3 cells were cotransfected with the Necdin or the pTRE reporter constructs, TR $\beta 0$ and increasing concentrations of NCoR expression plasmid. The cells were grown in the presence (solid bars) or absence (open bars) of $1 \mu \mathrm{M}$ T3 as indicated. The $y$-axis shows fold activation as a multiple of the luciferase value of the reporter vector alone (Necdin or pTRE). Standard deviations are shown from at least three independent experiments, each with triplicate samples. (B) The coactivator TIF2 is not required for TR-mediated regulation of Necdin. JEG-3 cells were cotransfected with the Necdin reporter construct, TR $\beta 0$ and increasing concentrations of TIF2 expression plasmid. The cells were grown in the presence (solid bars) or absence (open bars) of $1 \mu \mathrm{M}$ T3 as indicated. The $y$-axis shows fold activation as a multiple of the luciferase value of the reporter vector for Necdin alone. Standard deviations are shown from at least three independent experiments, each with triplicate samples.

shown in Fig. 4, where co-expression of RXR has no effect on the T3-induced repression of Necdin. It is not possible at this stage to determine if the association of NGoR to the Necdin promoter both in the presence and absence of $\mathrm{T} 3$ occurs through an interaction with both apo- and holoTR or if it is mediated through other transcription factors.

\section{Discussion}

Expression of the Necdin gene is regulated by the neuronal stem cell leukemia (NSGL) basic helix-loophelix factors NSCL-1 and NSCL-2, together with the Lim-domain-only cofactors in discrete regions of the hypothalamus (Kruger et al. 2004). The
NSCL-dependent control of Necdin is suggested to be instructive for differentiation and migration of gonadotrophin-releasing hormone neurons. Supporting the regulation of Necdin by NSGL-factors, the major symptoms of Prader-Willi syndrome such as obesity and hypogonadism resemble the phenotype of NSCL-2 knockout mice (Good et al. 1997). However, additional signalling pathways that regulate Necdin expression must exist, since the expression of Necdin outside the hypothalamus is not affected in NSCL-1 and -2 knockout mice (Kruger et al. 2004). This report identifies TR as a candidate regulator of Necdin transcription. In mice, Necdin expression is high in the brain just after birth and is down-regulated during the first 15 days postnatal period (results not shown). This period correlates with increasing circulating T3 levels, with T3 

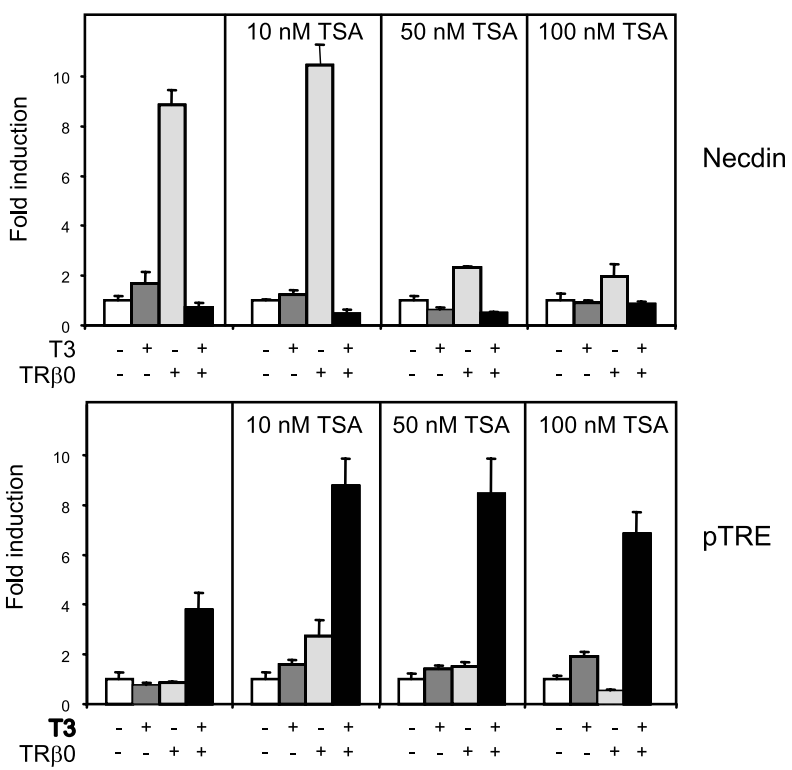

Figure 6 Trichostatin A (TSA) is not required for T3-dependent silencing of the Necdin luciferase reporter, but for

T3-independent activation of it. An expression vector of cTR $\beta 0$ was cotransfected with either the Necdin promoter coupled to a reporter gene (Necdin) or a reporter expressing a positive TR response element (pTRE) into JEG-3 cells, in the absence or presence of $1 \mu \mathrm{M} \mathrm{T3}$ and increasing concentrations of TSA, as indicated. The $y$-axis shows the fold induction as a multiple of the luciferase assay value of the reporter vector alone.

Standard deviations are shown from at least three independent experiments, each with triplicate samples.

affecting numerous functions in the brain in these first two weeks of life (Hadj-Sahraoui et al. 2000). However, a direct in vivo regulation of Necdin by T3 during this period remains to be investigated.

We have previously reported that the expression of E2F-1 and other S-phase progression factors such as thymidine kinase, DNA polymerase alpha and dihydropholate reductase are activated by apoTR and repressed in the presence of T3 (Nygård et al. 2003). These findings suggest that TR regulates the cell cycle by controlling the expression of cell cycle genes, a notion supported by the observation that mice with a TR $\beta$ mutation, deficient in ligand binding, induces formation of tumours in the pituitary as a consequence of an activated cyclinD1/cdk/rb/E2F pathway (Furumoto et al. 2005). In contrast to the proliferation-inducing effect of E2F-1, Necdin is highly expressed in postmitotic differentiating neurons and it has been suggested that it represses proliferation (Kuwako et al. 2004). The mechanism for suppression of proliferation by Necdin is similar to that of the retinoblastoma protein acting on $\mathrm{E} 2 \mathrm{~F}-1$, namely that Necdin binds to E2F-1 in post-mitotic neurons and thereby blocks its activity (Taniura et al. 1998). As shown by us, T3 down-regulates both the expression of E2F-1 and of Necdin, and could thereby mediate opposite effects on proliferation through these proteins.

There is as yet no clear consensus sequence for the nomenclature of nTREs. nTREs resembling pTREs have been reported, as well as several TR half sites and sequences completely unrelated to pTREs. There is also a difference in the reporting concerning monomer, homo- and heterodimer binding of TR to nTREs (Satoh et al. 1996, Taylor et al. 1996, Nygård et al. 2003, Shibusawa et al. 2003). We conclude here that the nTRE of the Necdin promoter is very homologous to the nTRE of the TSH $\beta$ genes (Fig. 1A). The identical 10 nucleotide sequence (known as the Z-element) shared between Necdin and TSH $\beta$ genes contains a potential TR half-site, AAGTAA, which is similar to the TR binding site referred to as site 'A' (AGGTAA) of the rat growth hormone promoter (Brent et al. 1989). Mutation of the $\mathrm{G}$ to $\mathrm{T}$ in this site totally abolishes TR regulation in the case of the Z-element of the human E2F-1 promoter (Nygård et al. 2003). Similarly, mutation of this $\mathrm{G}$ in the rat TSH $\beta$ promoter also abolishes ligandmediated repression (Carr \& Wong 1994). On the Necdin promoter, TR binds strongly to the nTRE as a heterodimer with RXR. This is in agreement with the requirement for RXR in transcriptional activation of Necdin (Figs 3 and 4). Our results indicate that the nTRE of the Necdin gene resembles the nTREs of the TSH $\beta$ genes both in terms of sequence and in the mode of activation through dimer binding, and requirements for RXR and NCoR for apoTR activation.

The mechanism for negative regulation by TR suggested by the experiments of this report partly resembles how the nTRE in the GH promoter is regulated (Sanchez-Pacheco \& Aranda 2003). By ChIP analysis the authors show that TR binds to the nTRE only in the absence of T3. Similarly, the ChIP analysis of the Necdin promoter in P19 cells suggested that TR and RXR are associated with the Necdin promoter mainly in the absence of T3 (Fig. 7B). Addition of T3 induced displacement of the TR/RXR complex, which according to Figs $1 \mathrm{~B}$ and 3 would be associated with repression of transcription. NGoR, on the other hand, remains on the promoter both in the presence and to some extent in the absence of T3 (Fig.7B). Also, we show that both NcoR association to TR and deacetylase activity is required for efficient ligand-independent activation of Necdin (Figs 3, 5A and 6). We cannot at this point determine whether the deacetylase activity is required for histone deacetylation or deacetylation of a nonhistone protein. However, in ChIP experiments we did not detect any significant changes in association of acetylated histones $\mathrm{H} 3$ and $\mathrm{H} 4$ with the Necdin promoter in the absence or presence of T3. The result that deacetylase activity is required for ligandindependent activation of Necdin expression contrasts with the findings by Tagami et al. (1999) and Sasaki et al. 


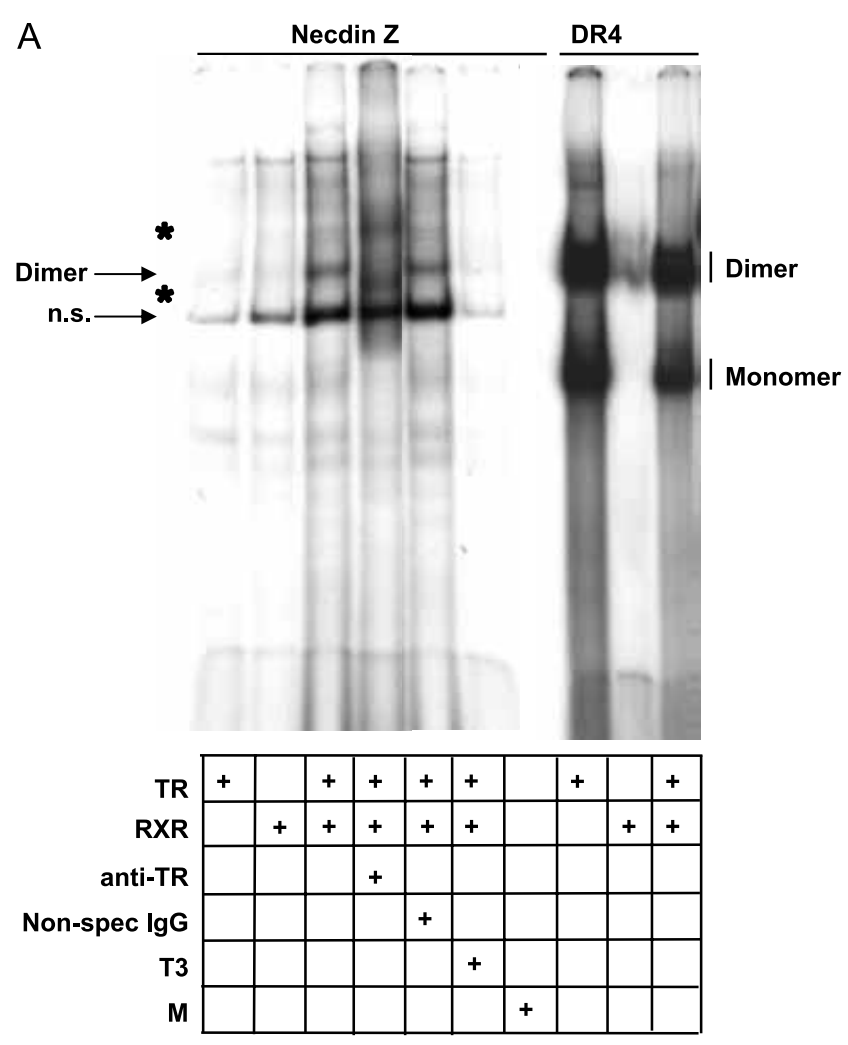

B mNecdin
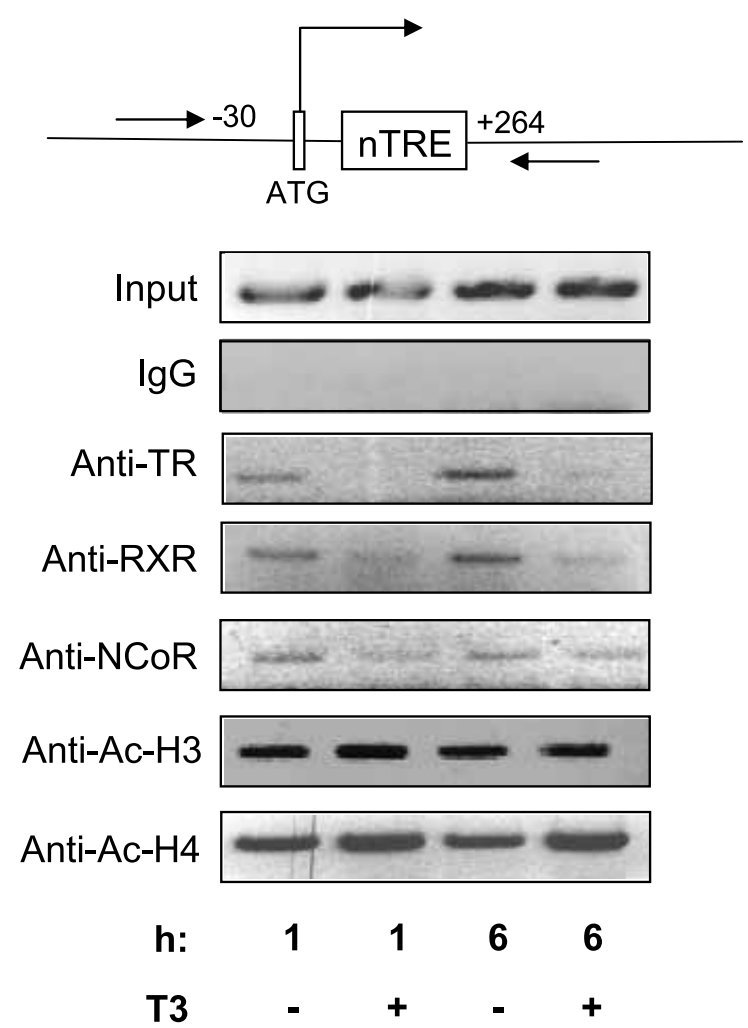

Figure 7 (A) TR binds to the Z-element as a heterodimer with RXR. Nuclear extracts were prepared by infection with Vaccinia virus vectors containing either TR $\beta$ or the retinoic $X$ receptor $(R X R \alpha)$ genes into HeLa cells or by mock infection (M). Extracts were incubated with labelled probes spanning the Z or DR4 elements and with an antibody against TR ( $\alpha$-TR $\beta)$, non-specific IgG $(\alpha-E R)$ or with $1 \mu \mathrm{M} \mathrm{T3}$ as indicated. Bound complexes were analysed on a $6 \%$ non-denaturating polyacrylamide gel. The DR4 element served as a marker for migration of monomers and heterodimers (TR/RXR) (Nygård et al. 2003). These bands are indicated, as well as supershifted complexes (*), and a non-specific band seen with the Necdin probe (n.s.). (B) Association of TR, RXR and $\mathrm{NCoR}$ with the Necdin promoter in vivo. Schematic representation of the $5^{\prime}$ region of the mouse Necdin gene. The nTRE and the translation (ATG) initiation sites are shown. Amplimers are highlighted by the arrows. ChIP assays were performed using extracts from retinoic acid-differentiated P19 cells treated with or without $1 \mu \mathrm{M}$ T3 for 1 or $6 \mathrm{~h}$. After sonication, samples were precipitated using antibodies against TR $\beta, R X R \beta, N C o R$ or acetylated histones $\mathrm{H} 3$ or $\mathrm{H} 4(\mathrm{Ac}-\mathrm{H} 3, \mathrm{Ac}-\mathrm{H} 4)$. DNA fragments were isolated and purified, and the levels of immunoprecipitated Necdin fragments were analysed by semi-quantitative PCR followed by agarose gel separation. Goat anti-rabbit IgG was used as a negative control.

(1999) who describe that it is only ligand-dependent repression of the $\mathrm{TSH} \alpha$ and $\beta$ promoters that requires HDAC activity. The discrepancies between these results will be investigated further. Other mechanisms besides histone acetylation, such as histone methylation and phosphorylation, are known to be important for TR to regulate transcription (reviewed by Li et al. 2002).

One of the enigmas in the field of thyroid hormone research has been that mice lacking both of the known TR receptors (TR $\alpha$ and TR $\beta$ ) display a milder phenotype than hypothyroid mice. Detailed analysis of double gene knockout mice has shown that the double knockouts have an extremely hyperactive pituitarythyroid axis, poor female fertility and retarded growth and bone maturation (reviewed by Forrest \& Vennstrom
2000, Flamant \& Samarut 2003). The TR knockout mice also show defects in cochlear and retinal development (reviewed by Forrest et al. 2002). Despite these defects, the brains of the TR knockout animals are surprisingly normal and the phenotype does not correspond to the gross hypothyroid-like phenotypes caused by T3 deficiency. The distinctions between T3 deficiency and receptor deficiency suggest that T3independent actions of $\mathrm{T} 3$ receptors may be a significant function in vivo and that apoTR may induce some of the profound and potentially irreversible defects of brain maturation that result from hypothyroidism. One possible explanation is that in the absence of ligand, abnormal regulation of transcription by the apoTR is responsible for the effects of profound hypothyroidism. 
This is supported by the result that congenitally hypothyroid, Pax 8-deficient mice that die during the first weeks of life, can be rescued by TR $\alpha 1$ gene deletion (Flamant et al. 2002). Another line of evidence for the adverse effects of apoTR is that mice expressing a mutated dominant negative TR, with a reduced ligand binding capacity, have a phenotype resembling that of hypothyroid mice (Hashimoto et al. 2001, Tinnikov et al. 2002). The negative effects of apoTR on development have been ascribed to constant repression of T3 target genes, at least in the amphibian system (Buchholz et al. 2003). However, considering the fact that in mammals T3 regulates as many genes negatively as positively (Feng et al. 2000), the developmental disturbances of apoTR could be caused by the inability to turn off the expression of negative thyroid hormone target genes. The Necdin gene appears to be one such gene, requiring down-regulation for normal development and being a potential mediator of the adverse effects of thyroid hormone deficiency. Such possibilities will be the focus of further investigations.

\section{Acknowledgements}

This work was supported by the European Commission funded CASCADE Network of Excellence (FOODCT2004-506319), the Swedish Research Council and the Novo Nordisk Foundation. The authors guarantee that there is no conflict of interest that would prejudice the impartiality of this work.

\section{References}

Andersson M \& Vennstrom B 2000 A choice between transcriptional enhancement and repression by the v-erbA oncoprotein governed by one nucleotide in a thyroid hormone responsive half site. Oncogene 19 3563-3569.

Andrieu D, Watrin F, Niinobe M, Yoshikawa K, Muscatelli F \& Fernandez PA 2003 Expression of the Prader-Willi gene Necdin during mouse nervous system development correlates with neuronal differentiation and p75 NTR expression. Gene Expression Patterns 3 761-765.

Awad TA, Bigler J, Ulmer JE, Hu YJ, Moore JM, Lutz M, Neiman PE, Collins SJ, Renkawitz R, Lobanenkov VV et al. 1999 Negative transcriptional regulation mediated by thyroid hormone response element 144 requires binding of the multivalent factor CTCF to a novel target DNA sequence. Fournal of Biological Chemistry $27427092-27098$.

Barettino D, Vivanco Ruiz MM \& Stunnenberg HG 1994 Characterization of the ligand-dependent transactivation domain of thyroid hormone receptor. EMBO Fournal 13 3039-3049.

Becker N, Seugnet I, Guissouma H, Dupre SM \& Demeneix BA 2001 Nuclear corepressor and silencing mediator of retinoic and thyroid hormone receptors corepressor expression is incompatible with T(3)-dependent TRH regulation. Endocrinology 142 5321-5331.

Berghagen H, Ragnhildstveit E, Krogsrud K, Thuestad G, Apriletti J \& Saatcioglu F 2002 Corepressor SMRT functions as a coactivator for thyroid hormone receptor T3 Ralpha from a negative hormone response element. Fournal of Biological Chemistry $27749517-49522$.

Bianco AC, Salvatore D, Gereben B, Berry MJ \& Larsen PR 2002 Biochemistry, cellular and molecular biology, and physiological roles of the iodothyronine selenodeiodinases. Endocrine Reviews 23 38-89.

Boeuf S, Klingenspor M, Van Hal NL, Schneider T, Keijer J \& Klaus S 2001 Differential gene expression in white and brown preadipocytes. Physiological Genomics 7 15-25.

Brent GA, Harney JW, Chen Y, Warne RL, Moore DD \& Larsen PR 1989 Mutations of the rat growth hormone promoter, which increase and decrease response to thyroid hormone, define a consensus thyroid hormone response element. Molecular Endocrinology 3 1996-2004.

Buchholz DR, Hsia SC, Fu L \& Shi YB 2003 A dominant-negative thyroid hormone receptor blocks amphibian metamorphosis by retaining corepressors at target genes. Molecular and Cellular Biology $236750-6758$.

Burakov D, Crofts LA, Chang CP \& Freedman LP 2002 Reciprocal recruitment of DRIP/mediator and p160 coactivator complexes in vivo by estrogen receptor. Fournal of Biological Chemistry 277 14359-14362.

Carr FE \& Wong NC 1994 Characteristics of a negative thyroid hormone response element. Fournal of Biological Chemistry $2694175-4179$.

Chakrabarti SK, James JC \& Mirmira RG 2002 Quantitative assessment of gene targeting in vitro and in vivo by the pancreatic transcription factor, Pdxl. Importance of chromatin structure in directing promoter binding. Fournal of Biological Chemistry 277 13286-13293.

Chin S, Apriletti J \& Gick G 1998 Characterization of a negative thyroid hormone response element in the rat sodium, potassium-adenosine triphosphatase alpha3 gene promoter. Endocrinology 139 3423-3431.

Collingwood TN, Rajanayagam O, Adams M, Wagner R, Cavailles V, Kalkhoven E, Matthews C, Nystrom E, Stenlof K, Lindstedt $\mathrm{G}$ et al. 1997 A natural transactivation mutation in the thyroid hormone beta receptor: impaired interaction with putative transcriptional mediators. PNAS 94 248-253.

Eckey M, Moehren U \& Baniahmad A 2003 Gene silencing by the thyroid hormone receptor. Molecular and Cellular Endocrinology $21313-22$.

Feng X, Jiang Y, Meltzer P \& Yen PM 2000 Thyroid hormone regulation of hepatic genes in vivo detected by complementary DNA microarray. Molecular Endocrinology 14 947-955.

Flamant F \& Samarut J 2003 Thyroid hormone receptors: lessons from knock-out and knock-in mutant mice. Trends in Endocrinological Metabolism 14 85-90.

Flamant F, Poguet AL, Plateroti M, Chassande O, Gauthier K, Streichenberger N, Mansouri A \& Samarut J 2002 Congenital hypothyroid Pax8(-/-) mutant mice can be rescued by inactivating the TRalpha gene. Molecular Endocrinology 16 24-32.

Forrest D \& Vennstrom B 2000 Functions of thyroid hormone receptors in mice. Thyroid $\mathbf{1 0} 41-52$.

Forrest D, Reh TA \& Rusch A 2002 Neurodevelopmental control by thyroid hormone receptors. Current Opinion in Neurobiology 12 49-56.

Furumoto H, Ying H, Chandramouli GV, Zhao L, Walker RL, Meltzer PS, Willingham MC \& Cheng SY 2005 An unliganded thyroid hormone beta receptor activates the cyclin D1/cyclin-dependent kinase/retinoblastoma/E2F pathway and induces pituitary tumorigenesis. Molecular and Cellular Biology 25 124-135.

Gerard M, Hernandez L, Wevrick R \& Stewart CL 1999 Disruption of the mouse Necdin gene results in early post-natal lethality. Nature Genetics 23 199-202.

Glozak MA, Sengupta N, Zhang X \& Seto E 2005 Acetylation and deacetylation of non-histone proteins. Gene 363 15-23. 
Good DJ, Porter FD, Mahon KA, Parlow AF, Westphal H \& Kirsch IR 1997 Hypogonadism and obesity in mice with a targeted deletion of the Nhlh2 gene. Nature Genetics 15 397-401.

Hadj-Sahraoui N, Seugnet I, Ghorbel MT \& Demeneix B 2000 Hypothyroidism prolongs mitotic activity in the post-natal mouse brain. Neuroscience Letters $28079-82$.

Hashimoto K, Curty FH, Borges PP, Lee CE, Abel ED, Elmquist JK, Cohen RN \& Wondisford FE 2001 An unliganded thyroid hormone receptor causes severe neurological dysfunction. PNAS 98 3998-4003.

Hollenberg AN, Monden T, Madura JP, Lee K \& Wondisford FE 1996 Function of nuclear corepressor protein on thyroid hormone response elements is regulated by the receptor A/B domain. Journal of Biological Chemistry $27128516-28520$.

Horlein AJ, Naar AM, Heinzel T, Torchia J, Gloss B, Kurokawa R, Ryan A, Kamei Y, Soderstrom M, Glass CK et al. 1995 Ligand-independent repression by the thyroid hormone receptor mediated by a nuclear receptor corepressor. Nature 377 397-404.

Hu B, Wang S, Zhang Y, Feghali CA, Dingman JR \& Wright TM 2003 A nuclear target for interleukin-1 alpha: interaction with the growth suppressor Necdin modulates proliferation and collagen expression. PNAS $10010008-10013$.

Kim SW, Hong SJ, Kim KM, Ho SC, So EC, Harney JW \& Larsen PR 2004 A novel cell type-specific mechanism for thyroid hormone-dependent negative regulation of the human type 1 deiodinase gene. Molecular Endocrinology 18 2924-2936.

Kim SW, Ho SC, Hong SJ, Kim KM, So EC, Christoffolete M \& Harney JW 2005 A novel mechanism of thyroid hormone-dependent negative regulation by thyroid hormone receptor, nuclear receptor corepressor $(\mathrm{NCoR})$, and GAGA-binding factor on the rat CD44 promoter. Fournal of Biological Chemistry 280 14545-14555.

Kruger M, Ruschke K \& Braun T 2004 NSCL-1 and NSCL-2 synergistically determine the fate of GnRH-1 neurons and control Necdin gene expression. EMBO Journal 23 4353-4364.

Kuwako K, Taniura H \& Yoshikawa K 2004 Necdin-related MAGE proteins differentially interact with the $\mathrm{E} 2 \mathrm{~F} 1$ transcription factor and the p75 neurotrophin receptor. Fournal of Biological Chemistry 279 1703-1712. Epub 2003 Oct 1729.

Laflamme L, Hamann G, Messier N, Maltais S \& Langlois MF 2002 RXR acts as a coregulator in the regulation of genes of the hypothalamo-pituitary axis by thyroid hormone receptors. Fournal of Molecular Endocrinology 29 61-72.

Li J, Lin Q, Yoon HG, Huang ZQ, Strahl BD, Allis CD \& Wong J 2002 Involvement of histone methylation and phosphorylation in regulation of transcription by thyroid hormone receptor. Molecular and Cellular Biology 22 5688-5697.

Liu YY, Tachiki KH \& Brent GA 2002 A targeted thyroid hormone receptor alpha gene dominant-negative mutation $(\mathrm{P} 398 \mathrm{H})$ selectively impairs gene expression in differentiated embryonic stem cells. Endocrinology $1432664-2672$.

Lopez G, Schaufele F, Webb P, Holloway JM, Baxter JD \& Kushner PJ 1993 Positive and negative modulation of Jun action by thyroid hormone receptor at a unique AP1 site. Molecular and Cellular Biology 13 3042-3049.

Maruyama K, Usami M, Aizawa T \& Yoshikawa K 1991 A novel brain-specific mRNA encoding nuclear protein (Necdin) expressed in neurally differentiated embryonal carcinoma cells. Biochemical and Biophysical Research Communications 178 291-296.

Mendez-Pertuz M, Sanchez-Pacheco A \& Aranda A 2003 The thyroid hormone receptor antagonizes CREB-mediated transcription. EMBO fournal 22 3102-3112.

Meng X, Webb P, Yang YF, Shuen M, Yousef AF, Baxter JD, Mymryk JS \& Walfish PG 2005 E1A and a nuclear receptor corepressor splice variant $(\mathrm{N}-\mathrm{CoRI})$ are thyroid hormone receptor coactivators that bind in the corepressor mode. PNAS $1026267-6272$.
Miller LD, McPhie P, Suzuki H, Kato Y, Liu ET \& Cheng SY 2004 Multi-tissue gene-expression analysis in a mouse model of thyroid hormone resistance. Genome Biology 5 R31.

Moore JM \& Guy RK 2005 Coregulator interactions with the thyroid hormone receptor. Molecular and Cellular Proteomics 4 475-482.

Muller P, Kietz S, Gustafsson J-Å \& Strom A 2002 The anti-estrogenic effect of all-trans-retinoic acid on the breast cancer cell line MCF-7 is dependent on the HES-1 expression. Fournal of Biological Chemistry 277 28376-28379.

Muscatelli F, Abrous DN, Massacrier A, Boccaccio I, Le Moal M, Cau P \& Cremer H 2000 Disruption of the mouse Necdin gene results in hypothalamic and behavioral alterations reminiscent of the human Prader-Willi syndrome. Human Molecular Genetics 9 3101-3110.

Nagaya T \& Jameson JL 1993 Thyroid hormone receptor dimerization is required for dominant negative inhibition by mutations that cause thyroid hormone resistance. Fournal of Biological Chemistry 268 15766-15771.

Nagaya T, Fujieda M \& Seo H 1998 Requirement of corepressor binding of thyroid hormone receptor mutants for dominant negative inhibition. Biochemical and Biophysical Research Communications $247620-623$.

Nakano K, Matsushita A, Sasaki S, Misawa H, Nishiyama K, Kashiwabara Y \& Nakamura H 2004 Thyroid-hormone-dependent negative regulation of thyrotropin beta gene by thyroid hormone receptors: study with a new experimental system using CV1 cells. Biochemical fournal 378 549-557.

Nygård M, Wahlstrom GM, Gustafsson MV, Tokumoto YM \& Bondesson M 2003 Hormone-dependent repression of the E2F-1 gene by thyroid hormone receptors. Molecular Endocrinology 17 79-92.

Ohman Forslund K \& Nordqvist K 2001 The melanoma antigen genes - any clues to their functions in normal tissues? Experimental Cell Research 265 185-194.

Poguet AL, Legrand C, Feng X, Yen PM, Meltzer P, Samarut J \& Flamant F 2003 Microarray analysis of knockout mice identifies cyclin D2 as a possible mediator for the action of thyroid hormone during the postnatal development of the cerebellum. Developmental Biology 254 188-199.

Quignodon L, Legrand C, Allioli N, Guadano-Ferraz A, Bernal J, Samarut J \& Flamant F 2004 Thyroid hormone signaling is highly heterogeneous during pre- and postnatal brain development. fournal of Molecular Endocrinology 33 467-476.

Rogister B, Ben-Hur T \& Dubois-Dalcq M 1999 From neural stem cells to myelinating oligodendrocytes. Molecular and Cellular Neuroscience 14 287-300.

Samuels HH, Stanley F \& Casanova J 1979 Depletion of L-3,5, $3^{\prime}$-triiodothyronine and L-thyroxine in euthyroid calf serum for use in cell culture studies of the action of thyroid hormone. Endocrinology 105 80-85.

Sanchez-Pacheco A \& Aranda A 2003 Binding of the thyroid hormone receptor to a negative element in the basal growth hormone promoter is associated with histone acetylation. Fournal of Biological Chemistry 278 39383-39391.

Sanchez-Pacheco A, Palomino T \& Aranda A 1995 Negative regulation of expression of the pituitary-specific transcription factor GHF-1/Pit-1 by thyroid hormones through interference with promoter enhancer elements. Molecular and Cellular Biology $156322-6330$.

Sasaki S, Lesoon-Wood LA, Dey A, Kuwata T, Weintraub BD, Humphrey G, Yang WM, Seto E, Yen PM, Howard BH \& Ozato K 1999 Ligand-induced recruitment of a histone deacetylase in the negative-feedback regulation of the thyrotropin beta gene. EMBO fournal 18 5389-5398.

Satoh T, Yamada M, Iwasaki T \& Mori M 1996 Negative regulation of the gene for the preprothyrotropin-releasing hormone from the mouse by thyroid hormone requires additional 
factors in conjunction with thyroid hormone receptors. Fournal of Biological Chemistry 271 27919-27926.

Satoh T, Monden T, Ishizuka T, Mitsuhashi T, Yamada M \& Mori M 1999 DNA binding and interaction with the nuclear receptor corepressor of thyroid hormone receptor are required for ligand-independent stimulation of the mouse preprothyrotropinreleasing hormone gene. Molecular and Cellular Endocrinology 154 137-149.

Shen X, Li QL, Brent GA \& Friedman TC 2004 Thyroid hormone regulation of prohormone convertase 1 (PC1): regional expression in rat brain and in vitro characterization of negative thyroid hormone response elements. Fournal of Molecular Endocrinology 33 21-33.

Shen X, Li QL, Brent GA \& Friedman TC 2005 Regulation of regional expression in rat brain $\mathrm{PC} 2$ by thyroid hormone/characterization of novel negative thyroid hormone response elements in the PC2 promoter. American fournal of Physiology, Endocrinology and Metabolism 288 E236-E245.

Shibusawa N, Hollenberg AN \& Wondisford FE 2003 Thyroid hormone receptor DNA binding is required for both positive and negative gene regulation. Fournal of Biological Chemistry $278732-738$.

Sjoberg M \& Vennstrom B 1995 Ligand-dependent and -independent transactivation by thyroid hormone receptor beta 2 is determined by the structure of the hormone response element. Molecular and Cellular Biology 15 4718-4726.

Tagami T, Park Y \& Jameson JL 1999 Mechanisms that mediate negative regulation of the thyroid-stimulating hormone alpha gene by the thyroid hormone receptor. Fournal of Biological Chemistry 274 22345-22353.

Taniguchi N, Taniura H, Niinobe M, Takayama C, Tominaga-Yoshino K, Ogura A \& Yoshikawa K 2000 The postmitotic growth suppressor Necdin interacts with a calcium-binding protein (NEFA) in neuronal cytoplasm. fournal of Biological Chemistry 275 31674-31681.

Taniura H, Taniguchi N, Hara M \& Yoshikawa K 1998 Necdin, a postmitotic neuron-specific growth suppressor, interacts with viral transforming proteins and cellular transcription factor E2F1. Fournal of Biological Chemistry 273 720-728.

Taylor AH, Wishart P, Lawless DE, Raymond J \& Wong NG 1996 Identification of functional positive and negative thyroid hormone-responsive elements in the rat apolipoprotein AI promoter. Biochemistry 35 8281-8288.

Tinnikov A, Nordstrom K, Thoren P, Kindblom JM, Malin S, Rozell B, Adams M, Rajanayagam O, Pettersson S, Ohlsson C et al. 2002 Retardation of post-natal development caused by a negatively acting thyroid hormone receptor alphal. EMBO fournal 21 5079-5087.

Vasudevan N, Kia HK, Hadjimarkou M, Koibuchi N, Chin WW, Forrest D, Vennstrom B \& Pfaff D 2005 Retinoid-related receptor (ROR) alpha mRNA expression is altered in the brain of male mice lacking all ligand-binding thyroid hormone receptor (TR) isoforms. Endocrine 26 25-32.

Villa A, Santiago J, Belandia B \& Pascual A 2004 A response unit in the first exon of the beta-amyloid precursor protein gene containing thyroid hormone receptor and Spl binding sites mediates negative regulation by $3,5,3^{\prime}$-triiodothyronine. Molecular Endocrinology 18 863-873.

Yoshikawa K 2000 Cell cycle regulators in neural stem cells and postmitotic neurons. Neuroscience Research 37 1-14.

Zoeller RT \& Rovet J 2004 Timing of thyroid hormone action in the developing brain: clinical observations and experimental findings. Fournal of Neuroendocrinology 16 809-818.

Received in final form12 December 2005

Accepted 13 February 2006 